\title{
Ferramenta integrada de produção e compartilhamento de REAs
}

\author{
Cícero J. P. dos Santos ${ }^{1}$, Francisco K. de Oliveira ${ }^{2}$ \\ ${ }^{1}$ Sistemas Para Internet - Instituto Federal de Educação, Ciência e Tecnologia do Sertão \\ Pernambucano - Campus Salgueiro; \\ ${ }^{2}$ Instituto Federal de Educação, Ciência e Tecnologia do Sertão Pernambucano - \\ Campus Salgueiro; \\ ${ }^{1}$ E-mail: cjosinaldopatricio@gmail.com, \\ ${ }^{2}$ E-mail: francisco.oliveiraeifsertao-pe.edu.br.
}

\begin{abstract}
Resumo. Este trabalho visa conceber um ambiente Web integrado de armazenamento, criação, edição e compartilhamento de recursos educacionais abertos (REA). Assim, será possível ter todas as funções mencionadas em apenas um único sistema on-line, inclusive com a possibilidade dos REAs salvos ou criados nesta plataforma serem incorporados ou indexados por outras. Para isso, foi realizada uma análise de competidores que mostrou a indisponibilidade de exemplo semelhante que realize todas essas funcionalidades. Almeja-se que tal ambiente promova o aumento da produção de REAs e esses REAs possibilitem novas práticas educacionais abertas (PEAs), que possam ser utilizadas, reutilizadas ou modificadas nos mais diversos contextos educacionais.
\end{abstract}

\section{Cenário de uso}

Através da inserção das tecnologias digitais de informação e comunicação (TDICs) nos propósitos educacionais busca-se trazer melhorias significativas ao processo de ensino e aprendizagem mediante a criação de conteúdos didáticos digitais. O problema é que parte dos materiais disponibilizados na rede encontra-se sob licenças proprietárias, restringindo seu uso e manipulação a um grupo específico de indivíduos. Neste cenário uma solução viável é a aplicação dos Recursos Educacionais Abertos (REAs) atuando em conjunto com as TDICs.

Para Matias et al. (2016), os REAs consistem em materiais de apoio à educação disponibilizados e compartilhados de forma livre e aberta nos mais diversos formatos e meios de comunicação, tal qual a comunicação via Internet, sob licença livre ou domínio público com base na educação aberta. Mantendo o contexto da criação e difusão do conhecimento, uma característica interessante dos REAs é a possibilidade de adaptação às várias situações dos usuários, por exemplo, um docente poderia acessar e adaptar à sua aula o plano de aula disponibilizado por outro docente. Isto se deve, principalmente, às liberdades 5R's, a saber, Reutilizar, Revisar, Remixar, Redistribuir e Reter os REAs (MAZZARDO, NOBRE \& MALLMANN, 2016). 
Muitos programas e projetos baseados no uso das tecnologias digitais de informação e comunicação foram implementados e implantados em escolas e instituições de ensino com a intenção de impactar positivamente no processo de ensino e aprendizagem dos docentes e discentes em várias modalidades de educação e trazer benefícios satisfatórios, (OLIVEIRA, 2015). Contudo, é importante enfatizar que não basta somente empregar as TDICs na educação, para atingir os resultados almejados é preciso realizar um estudo com antecedência frisando os principais aspectos e situações vivenciadas pelos docentes e discentes. Outro fator que reduz a eficácia dos projetos é a utilização de materiais mantidos e protegidos por licenças privadas de autoria, este fator limita o uso dos materiais a um determinado grupo de usuários, assim como não possui o privilégio de adaptação por parte dos docentes.

Diante disso, há a necessidade de aplicar as TDICs nos contextos educacionais específicos, bem como adaptar os recursos didáticos utilizados nas aulas à realidade dos professores e alunos e, também, disseminar estes recursos às organizações, às instituições de ensino e aos demais públicos interessados. Tal necessidade justifica o desenvolvimento e implantação de um sistema computacional de colaboração no âmbito educacional que possibilite a criação, revisão, reutilização, retenção, remixagem e o compartilhamento dos REAs em meio digital.

\section{Desenvolvimento}

Primeiramente, para desenvolver esse sistema é de fundamental importância realizar uma análise de competidores de natureza exploratória a fim de identificar os ambientes e ferramentas de compartilhamento de REAs já implantados e em funcionamento para servir como ponto de partida ao desenvolvimento.

Os requisitos de software necessários para implementar esse protótipo correspondem a aplicativos livres e isentos de pagamentos adicionais do licenciamento. Tais como editores de textos puros, suítes de escritório livres, frameworks de programação na web gratuitos, Sistemas de Gerenciamento de Banco de Dados (SGBDs), browsers e servidores web, seja hospedados localmente ou hospedados na nuvem.

Além disso, adotou-se o uso da ferramenta de gerenciamento, criação e execução de containers, Docker, para instanciar as imagens de containers de repositório, o que permitiu integrar as aplicações e funcionalidades a um sistema de repositório existente. No contexto do projeto, tal ferramenta proporcionou maiores eficiência e eficácia, especialmente, devido à sua pequena curva de aprendizagem, seu enorme potencial no desenvolvimento e sua facilidade de manuseio, o que ocasionou um melhor aproveitamento de tempo na execução do projeto.

O protocolo aberto de autorização, OAuth, é uma forma padronizada, simples e segura de estabelecer a comunicação entre aplicações e serviços na Web, (https://oauth.net). Através deste protocolo realizou-se as integrações entre os serviços Web do Google Docs com o ambiente RECREIO. 
VIII Congresso Brasileiro de Informática na Educação (CBIE 2019)

Anais dos Workshops do VIII Congresso Brasileiro de Informática na Educação (WCBIE 2019)

\section{Apresentação do Software}

O RECREIO (Repositório de Compartilhamento de Recursos Educacionais Interativos e Online) consiste numa plataforma Web, bastando somente acessar a página do site e criar um cadastro, que é capaz de armazenar os recursos educacionais submetidos e fornecer mecanismos de busca e ferramentas de autoria suficientes para criação, edição, uso e compartilhamento destes recursos, dentre outros serviços.

Esta proposta visa facilitar o trabalho de desenvolvimento de materiais didáticos digitais por parte dos docentes, tendo em vista mitigar as limitações, por ora existentes, dentre as quais destacam-se:

- Impossibilidade de reaproveitamento dos materiais por outros professores e/ou pesquisadores interessados, já que os materiais não estão armazenados e acessíveis para todos;

- Limitações de adequação dos materiais devido às licenças e direitos autorais que restringem o seu uso;

- Ociosidade dos materiais em razão do seu desuso e da chegada de outros novos e atualizados, ou seja, os materiais que não são disseminados e readaptados nos contextos educacionais em pouco tempo ficarão desatualizados e irão precisar ser recriados, o que acarreta em mais tempo e esforço na produção.

Dessa forma, o RECREIO tem por objetivo auxiliar os professores e alunos no processo de ensino e aprendizagem por meio das práticas de colaboração mútua, tais como compartilhamentos de cursos, produções intelectuais e acadêmicas, planos de aula, banco de questões, produção de conteúdos, entre outras. Além do mais, com sua utilização por instituições e organizações de ensino, tanto públicas quanto privadas, seria possível obter-se um canal de comunicação unificado que conectaria todos os envolvidos em um ambiente integrado.

Vale destacar que uma característica fundamental e diferencial desta proposta está na possibilidade de elaboração dos recursos na própria plataforma online, dispensando a necessidade de o usuário utilizar software terceiros para tal finalidade. A oferta das opções de criar/editar ocorreria através das integrações com ferramentas de edição e gerenciamento de texto, slide, planilha eletrônica, imagens, objetos em linguagem de marcação, etc.

Quando o usuário entra na página principal do site, é apresentada a tela inicial para os usuários visitantes, ou seja, não possuem uma conta ou não estão logados nela. A partir desta tela os usuários podem visualizar os materiais disponíveis na plataforma navegando entre os links e botões presentes. A figura 1 é a tela principal e de boas vindas aos usuários do ambiente, de início ela passa a ideia de que o usuário trabalhará com REAs. 
VIII Congresso Brasileiro de Informática na Educação (CBIE 2019)

Anais dos Workshops do VIII Congresso Brasileiro de Informática na Educação (WCBIE 2019)

\section{Bem Vindo ao RECREIO!}

Este é seu ambiente de criação, edição, uso, reuso e compartilhamento de Recursos Educacionais Abertos Desfrute de nossas ferramentas para espalhar o conhecimento!

\section{Recursos Educacionais Abertos}

Figura 1. Tela principal do repositório.

Fonte: <https://recreio.000webhostapp.com/index.html>

Para os usuários já cadastrados, faz-se necessário selecionar o botão "Login", localizado no canto superior direito da tela inicial (Figura 1). Após isto, aparecerá a tela de login para autenticação do usuário e acesso à conta cadastrada através do endereço de e-mail e a senha do usuário, informados no ato do cadastramento, conforme a figura 02 apresenta.

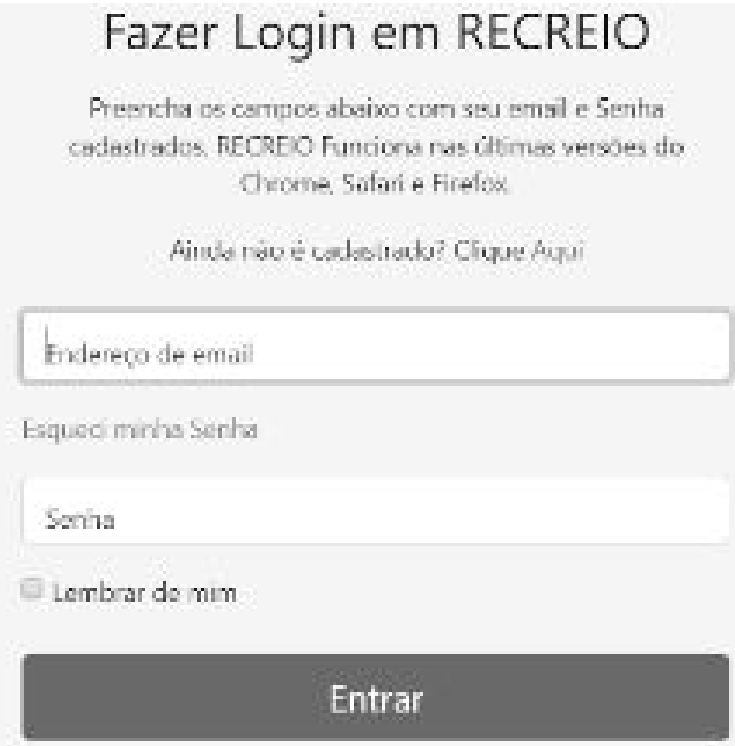

Figura 2. Tela de Login.

Fonte: <https://recreio.000webhostapp.com/login.html>

Em contrapartida, caso o usuário ainda não seja cadastrado no sistema, o caminho a ser seguido é selecionar a opção "Cadastrar", localizada no canto superior direito da tela inicial (Figura 1) e preencher devidamente os campos obrigatórios com os dados requeridos.

Uma vez realizados o cadastro e a confirmação dos dados informados pelo usuário, ele já pode efetuar o login para ter acesso a sua conta. A figura 2 ilustra a tela principal do repositório para os usuários cadastrados. Nela são apresentados as 
VIII Congresso Brasileiro de Informática na Educação (CBIE 2019)

Anais dos Workshops do VIII Congresso Brasileiro de Informática na Educação (WCBIE 2019)

atividades realizadas recentemente, assim também os arquivos e diretórios contidos no repositório.

Ainda nesta tela, Figura 1, os usuários possuem as funcionalidades de navegar pelos diretórios do repositório e fazer o Download e Upload de recursos. Ao selecionar, no menu principal, a opção "Arquivos Compartilhados" o usuário será direcionado à área do repositório que apresenta os recursos compartilhados. Além disso, esta área tem a funcionalidade de criar novos recursos, tal qual ocorre na tela a seguir, Figura 3.

\section{Biblioteca de Recursos Armazenados}

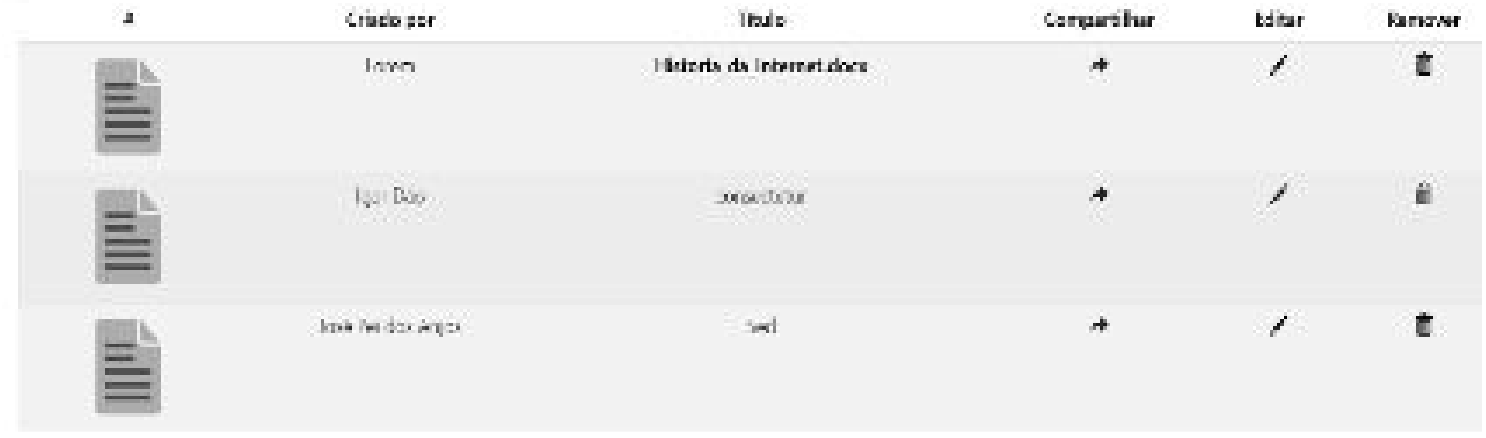

Figura 3. Tela de Arquivos Compartilhados.

Fonte: <https://recreio.000webhostapp.com/compartilhados.html>

Adotou-se como exemplo de funcionamento do repositório a criação de um documento do tipo texto, tal qual é demonstrado na Figura 4. Subsequente à criação, o usuário será solicitado a conectar-se a uma conta do Google, pois, como foi mencionado na seção anterior, o RECREIO também está vinculado aos serviços do Google Docs. O resultado detalhado da criação é apresentado na Figura 4.

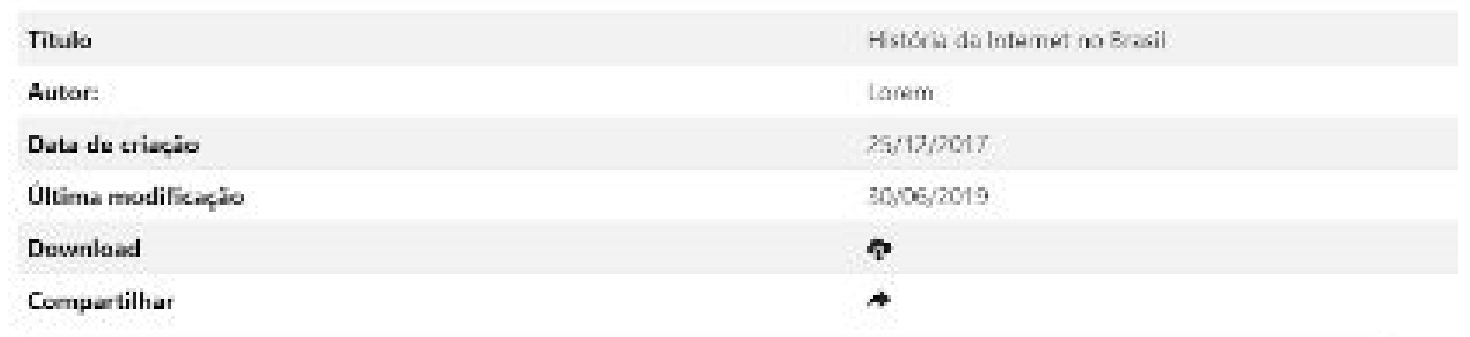

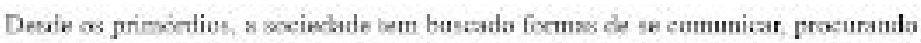

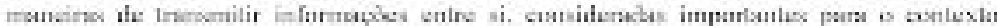

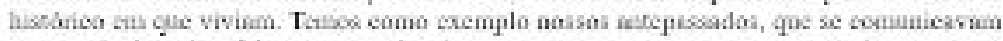

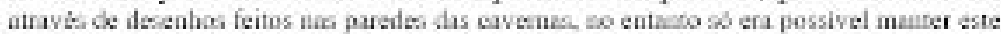
tipo de cocracicacto se todac as pessous ertiveceem no meraso losal. Com o pocese do vempo varios inventos foram surzindo com o intuito de facilines comunicsesto entre vessags que estivessem em lacsis disinarea. 
VIII Congresso Brasileiro de Informática na Educação (CBIE 2019)

Anais dos Workshops do VIII Congresso Brasileiro de Informática na Educação (WCBIE 2019)

Figura 4. Tela de criação de recurso do tipo texto.

Fonte: <https://recreio.000webhostapp.com/doc.html>

O documento criado com auxílio dos serviços do Google Docs pode ser facilmente executado e editado através de aplicações para Desktop vinculadas à plataforma RECREIO, como por exemplo as suítes de escritórios LibreOffice e o pacote MSOffice. Com isto, os usuários têm autonomia para criar e editar seus recursos independentemente da conexão com a Internet.

Além do mais, o usuário autor ainda pode definir metadados descritivos para facilitar a localização dos recursos pelos mecanismos de busca, assim como, pode compartilhar o recurso recém criado em grupos aos quais esteja associado, pessoas específicas e/ou em RSE (Rede Social Educacional), tais como o OpenRedu e Edmodo. Ainda existe a possibilidade de compartilhamento de recursos em meio a AVAs (Ambiente Virtual de Aprendizagem), por exemplo o Moodle. A Figura 4 apresenta a tela de seleção do ambiente para compartilhamento de recurso após o usuário acionar a opção de "Compartilhar".

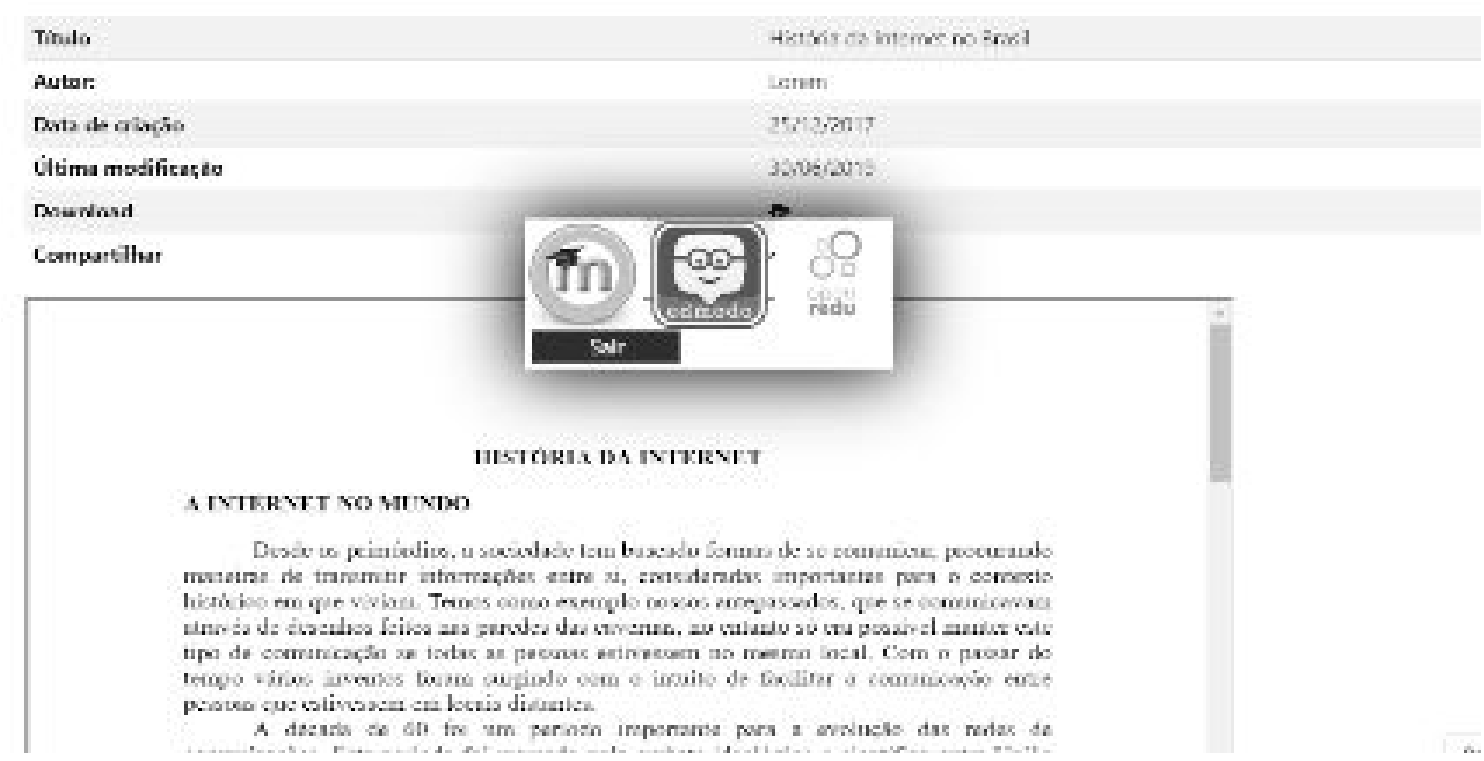

Figura 5. Tela de forma de compartilhamento do recurso

Fonte: <https://recreio.000webhostapp.com/doc.html>

Passada essa etapa, o usuário poderá selecionar novamente a opção “Arquivos Compartilhados" no menu principal da página para constatar que o recurso criado e compartilhado localiza-se armazenado no repositório, assim como é ilustrado pela Figura 4. Bastando, para reabrir o documento, selecioná-lo e realizar o Check in no Google Docs ou utilizar um editor integrado, tal qual o LibreOffice.

Por fim, o usuário cadastrado ainda pode fazer consultas e encontrar outros usuários através dos mecanismos de busca por caracteres dos nomes, um exemplo de busca está contido na Figura 6. No exemplo da Figura 6 foi informado o caractere "a" para filtrar os resultados e obteve-se os usuários que contêm este mesmo caractere no nome. A partir deste ponto, o usuário pode marcar as pessoas encontradas na busca acionando o botão "Seguir" localizado à direita de cada pessoa. 
VIII Congresso Brasileiro de Informática na Educação (CBIE 2019)

Anais dos Workshops do VIII Congresso Brasileiro de Informática na Educação (WCBIE 2019)

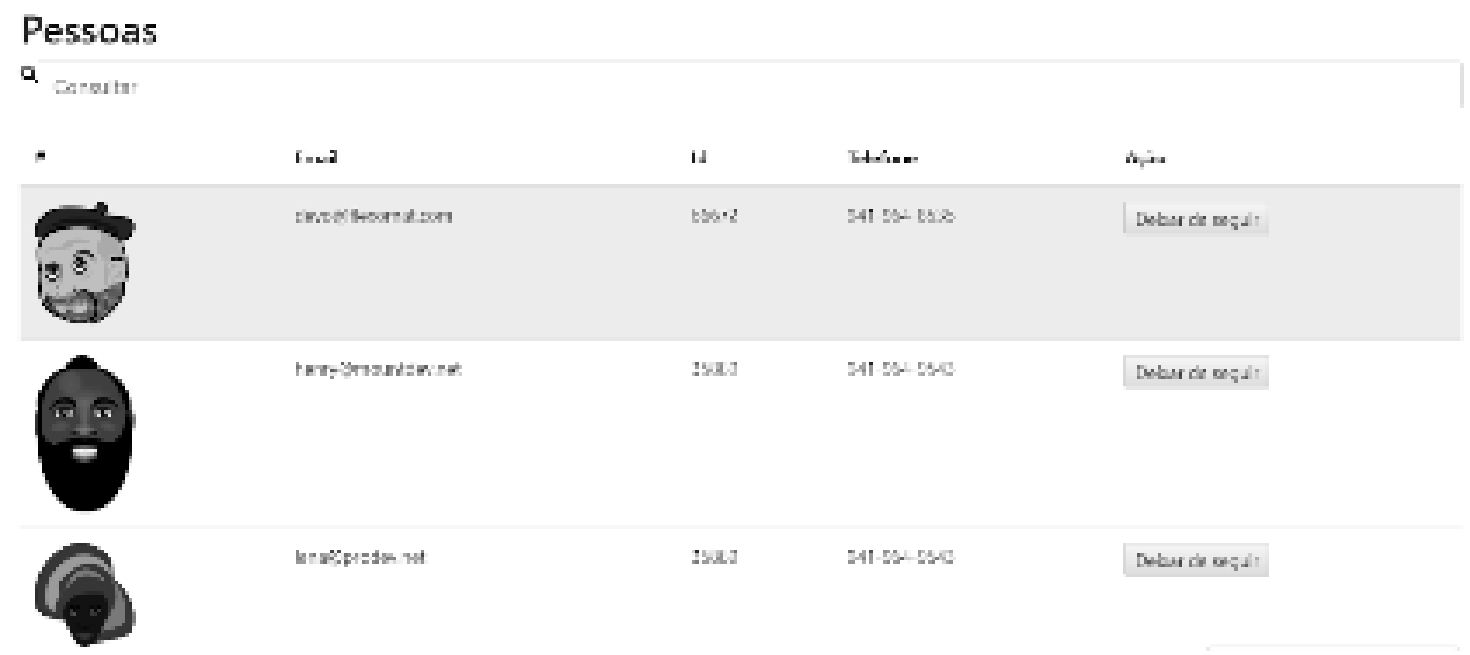

Figura 6. Tela de busca de pessoas

Fonte: <https://recreio.000webhostapp.com/pessoas.html>

Assim sendo, em comparação aos repositórios e ambientes institucionais existentes e implantados na atualidade, este protótipo possui os diferenciais de criação, edição e compartilhamento de REAs, nos mais variados formatos e temáticas, mediante o uso das TDICs em conjunto com a Internet de forma livre, gratuita e aberta com foco prioritário na sua aplicabilidade em âmbito educacional. Desta forma, ele poderá ser uma ferramenta de bastante ajuda aos docentes que desejarem criar seus próprios recursos, (OLIVEIRA, 2017).

A seção subsequente apresentará as possibilidades de aplicação deste protótipo, assim também o fechamento deste trabalho e as propostas para trabalhos futuros. Para auxiliar na compreensão do protótipo, encontra-se disponibilizado em (https://youtu.be/NuWmgUfWOIY) um vídeo introdutório que apresenta as principais características deste protótipo.

\section{Considerações finais}

Com o avanço das TDICs minimizou-se consideravelmente o grau de complexidade para professores e pesquisadores produzirem materiais de apoio à educação e aplicarem tais materiais em sala de aula.

A plataforma do RECREIO é formada por um conjunto de ferramentas e serviços para propiciar aos seus usuários as funcionalidades de trabalho com REA. Esta plataforma é apresentada como uma forma de aprimoramento da reutilização, revisão, remixagem, redistribuição e retenção dos REAs, já que propõe agregar os valores das TDICs com o poder de comunicação da Internet através de integrações por protocolos e Rest APIs em um ambiente integrado online.

Convém ressaltar que o protótipo apenas transmite a ideia principal da plataforma propriamente dita, logo este não está integrado às ferramentas de edição e, por isso, não fornece tais serviços. 
Esta é uma ferramenta sob licenciamento livre para uso, estudo e adaptação, bem como, por se tratar de um ambiente na Web, não requer muitos recursos computacionais das máquinas dos usuários finais. Estas características reduzem gastos adicionais e permitem sua implantação em instituições e organizações de ensino tanto públicas quanto privadas.

Espera-se que este protótipo possa servir como incentivo ao uso, criação e compartilhamento de recursos educacionais abertos entre instituições, organizações, docentes e pesquisadores em âmbito educacional.

Sugere-se, portanto, para trabalhos futuros realizar testes de usabilidade com os usuários finais do sistema e integrar interpretadores, compiladores e ambientes de desenvolvimento integrado para que o RECREIO possa oferecer suporte à implementação e testes de aplicações educacionais, tais como jogos educativos, diretamente na plataforma Web.

\section{Referências}

Mallmann, E. Ma .. (2018) Massive/Small Open Online Courses (MOOC/SOOC) e Recursos Educacionais Abertos (REA): inovação disruptiva na educação online e aberta. Revista Diálogo Educacional, v. 18, n. 56. Disponível em: https://periodicos.pucpr.br/index.php/dialogoeducacional/article/view/23599 Acesso em: 15 jun. 2018.

Matias, P. H. B. et al. (2016) Ambiente de compartilhamento de REAs: uma proposta de modelagem, implementação e modelo de negócio. Revista Semiárido De Visu, v. 4, n. $1, \quad$ p. 18-31. $\quad$ Disponível em https://periodicos.ifsertao-pe.edu.br/ojs2/index.php/revista/article/view/195 Acesso em 15 de Jun de 2018.

Mazzardo, M. D., Nobre, A., \& Mallmann, E. M. (2016). Professores efetivando os 5Rs de abertura dos REAs. [Em linha] : revista de educação para o século XXI. ISSN 2183-7988. $\quad \mathrm{N}^{\mathrm{o}} \quad 2, \quad 10 \quad$ p. $\quad$ Disponível em https://repositorioaberto.uab.pt/handle/10400.2/5736 Acesso em 30 de Jun de 2018.

Oliveira, F. K.; ABREU, Kélvya Freitas; DA SILVA GOMES, Antônio Anderson. (2016) Formação profissional em recursos educacionais abertos. Revista Semiárido De Visu, v. 3, n. 2, p. 98-109. Disponível em https://periodicos.ifsertao-pe.edu.br/ojs2/index.php/revista/article/view/205 Acesso em 15 de Jun de 2018.

Oliveira, F. K., de Oliveira, M. B., Gomes, A. S., \& Queiros, L. M. (2017). RECREIO: Floss as SAAS for sharing of educational resources. In Information Systems and Technologies (CISTI), 2017 12th Iberian Conference on (pp. 1-6). IEEE. Disponível em https://ieeexplore.ieee.org/abstract/document/7975929/ Acesso em 30 de Jun de 2018. 